\title{
KNOWLEDGE AND THE OBJECTION TO RELIGIOUS BELIEF FROM COGNITIVE SCIENCE
}

\author{
KELLY JAMES CLARK \& DANI RABINOWITZ \\ Calvin College Oxford University
}

\begin{abstract}
A large chorus of voices has grown around the claim that theistic belief is epistemically suspect since, as some cognitive scientists have hypothesized, such beliefs are a byproduct of cognitive mechanisms which evolved for rather different adaptive purposes. This paper begins with an overview of the pertinent cognitive science followed by a short discussion of some relevant epistemic concepts. Working from within a largely Williamsonian framework, we then present two different ways in which this research can be formulated into an argument against theistic belief. We argue that neither version works. ${ }^{1}$
\end{abstract}

Belief in gods requires no special parts of the brain. Belief in gods requires no special mystical experiences, though it may be aided by such experiences. Belief in gods requires no coercion or brainwashing or special persuasive techniques. Rather, belief in gods arises because of the natural functioning of completely normal mental tools working in common natural and social contexts.

Barrett (2004: 21)

I.

Theism is no stranger to attack. In its long and checkered history it has faced a barrage of tough assaults on its veracity. Some of these challenges, like the problem of evil, remain unresolved. The scientific revolution marked the beginning of a particularly difficult period for theism, with these difficulties intensified by modern science. Today

${ }^{1}$ Thanks to John Hawthorne, Michael Murray, Justin Barrett, and Alvin Plantinga for helpful comments on a previous draft of this paper. 
the science vs. theism debate is an industry of its own. In recent years a growing number of atheists have made recourse to some of the findings in contemporary cognitive science to formulate a novel challenge to theistic belief. According to several psychologists, anthropologists, evolutionary theorists, and cognitive scientists, the human mind evolved in such a way that it is naturally drawn towards belief in disembodied, supernatural agents, the God of monotheism being just one such agent. The belief that God exists, according to most defenders of this view, is an accidental byproduct of certain cognitive mechanisms that evolved for rather different adaptive purposes. Richard Dawkins (2006: 200-22) and Daniel Dennett (2006), for example, make use of this research in their case against theism. ${ }^{2}$ Whilst neither explicitly claims that in virtue of this research there is something epistemically suspect about the belief that God exists, the innuendo is obvious. Dawkins contends that these findings partly explain why it is that people acquire and maintain the delusion that God exists, whilst for Dennett this research breaks the spell that binds us to religious belief.

Since no formal arguments are presented, it remains unclear how the research in the cognitive science of religion (CSR) can be used to undermine the epistemic status of the belief that God exists (hereafter the CSR objection). Some, e.g., Murray (2009) and Clark and Barrett (2010, forthcoming) have taken up the challenge of proposing different ways in which such arguments could be formulated to the conclusion that religious beliefs are irrational. This paper is a continuation of this line of work but differs in two respects. Firstly, we consider how the CSR objection might be understood in terms of Timothy Williamson's knowledge-first framework. Secondly, in light of the significant role that testimony plays in the acquisition and transmission of religious belief, we consider the role the epistemology of testimony could play in the CSR objection. $\$ 2$ begins with a presentation of the relevant aspects of the CSR research. Thereafter follows a brief explanation of Williamson's claim that safe belief is a necessary condition for knowledge. A treatment of several epistemic terms of art concludes $\$ 2$. In $\$ 3$ we present two different ways in which the CSR research can be formulated into an

${ }^{2}$ See also Atran (2002), Bering (2006, 2011), Bloom (2005), Boyer (2001), and Wilson (2002). 
argument to the effect that the belief that God exists is unsafe. We argue that neither version works.

II.

\subsection{The Cognitive Science of Religion}

Owing to differences in methodologies and research goals, there is unfortunately no definitive statement of the cognitive and evolutionary psychology of religion. For our purposes it will suffice to draw attention to the work of Justin Barrett $(2004,2009)$, a dominant figure in the CSR literature. Here is a rough sketch of Barrett's theory.

Human beings are naturally prone to develop a certain class of concepts that Barrett labels "minimally counterintuitive concepts" (MCIs). A MCI is a standard concept that has been augmented in some rather unusual ways such that it becomes attention-grabbing; easy to understand and remember; and has the capacity to feature in the explanation of many events. A "talking shoe" or an "invisible dog" are examples of MCIs. It is not unusual to find disparate groups, despite having no contact with one another, having many MCIs in common. The concept of a "god" is an example of a common MCI, where a "god" is a disembodied, supernatural agent. Eventually the concept "God" developed where that term denotes the God of monotheism.

The mental configuration of human beings also includes an Agency Detecting Device (ADD) that disposes us to detect agency in our environment. Since ADD is sometimes triggered on the slenderest of bases, this so-called hypersensitive agency detection device (HADD) often registers false positives. With respect to evolutionary psychology, possessing such a hypersensitive device has survival advantages since the speedy and non-inferential detection of an agent in the vicinity (a predator, say, or a potential mate) would have led to greater reproductive success. Once the presence of an agent is registered a second mental tool kicks in. This tool, commonly termed "Theory of Mind" (ToM), attributes a mental life to the detected agent, where such attributions typically concern what desires or intentions that agent might have vis-àvis the subject. 
At a point in our history some primitive peoples perceived a state of affairs that resulted in HADD triggering a belief in the presence of an agent. With the aid of ToM, the state of affairs made sense in virtue of an agent acting in such-and-such a way with such-and-such intentions. However, only agents with MCI concepts of god-like agents could explain what they had perceived, as no natural explanation adequately accounted for these circumstances. As a result human beings came to believe that God exists. In some cases the order of explanation is in the reverse-the MCI "God" developed on its own apart from such inexplicable states of affairs. Only much later did certain human beings retroactively understand said states of affairs in terms of God's actions.

\subsection{Knowledge as Safe Belief}

Knowledge, for Williamson (2000), requires avoidance of error in similar enough cases. The basic idea is that $S$ knows $P$ only if $S$ is safe from error, where being safe means that there must be no risk or danger that $S$ falsely believes in a relevantly similar case. Knowledge, then, requires a margin for error; that is, cases in which $S$ knows $P$ must be buffered by cases of true belief. The relevant modal notions of safety, risk, and danger are cashed out in terms of possible worlds such that a margin for error is created in so far as there is no close world in which $S$ falls into error. Such worlds act as a "buffer zone" from error and thereby prevent the type of epistemic luck that characterizes Gettier cases. ${ }^{3}$ Here is one pertinent formulation of the safety condition:

If in a case $\alpha$ one knows $p$ on a basis $B$, then in any case close to $\alpha$ in which one believes a proposition $p^{*}$ close to $p$ on a basis $\left[B^{\star}\right]$ close to $B$, then $p^{*}$ is true (Williamson 2009: 325).

For example, $S$ does not know that it's noon by looking at a broken clock correctly reading noon since there is a close world in which $S$ believes falsely e.g. a world in which $S$ looks at the broken clock slightly before or after noon or where the broken clock incorrectly reads 12:02.

\footnotetext{
${ }^{3}$ See Gettier (1963) and Shope (1983).
} 
Unlike the aforementioned authors, we grapple with the CSR objection in terms of knowledge and not in terms of rationality. There are several reasons for this difference in strategy. Firstly, since those putting forward the CSR objection do not explicitly state that religious beliefs are irrational in virtue of findings in cognitive science and evolutionary psychology, prima facie there is no reason to interpret their challenge in terms of rationality instead of knowledge, especially if knowledge is the more primitive concept of the two. ${ }^{4}$ Given the current popularity of explications of knowledge in terms of safe belief, Williamson's safety condition is a natural choice seeing that he is one of the more influential safety theorists. ${ }^{5}$

Secondly, most agree that knowledge is non-accidentally true belief. However, there is no such consensus to be found amongst those working on rationality. Whilst some consider rationality to be the degree to which evidence increases the probability of a belief's being true, others see it as a property that supervenes on the reliability of cognitive mechanisms. And yet others deem it to be a kind of self-reflective state. As such some see rationality as being determined from an external point of view whilst others from an internal point of view. And the concepts of rationality that result from such divergent approaches can be radically different. By concentrating on knowledge as opposed to rationality we avoid this murky and contested territory.

Thirdly, given that the CSR research concerns the accidental nature by which theistic belief arose, one natural concern would be that theistic belief is accidentally true or unsafe. It would not make sense, then, to formulate arguments against theistic belief on the basis of the CSR research in terms of rationality for on most accounts of rationality an agent $S$ may be rational in believing $p$ despite $S$ s being lucky that $p$ is true.

Finally, there is good reason to think that the appropriate norm for assertion and practical reasoning is knowledge and not justified or rational belief (Williamson 2000: 238ff; Hawthorne and Stanley 2008). Since theistic belief is often the subject of assertion and, more importantly, influences the way theists go about living their lives, it makes sense to worry about whether theists can know that God exists in light of the

${ }^{4}$ For arguments to the effect that knowledge is a primitive concept, see Williamson (2000: 2-5).

${ }^{5}$ Sosa $(1999)$ and Pritchard $(2005,2009)$ are the other two influential safety theorists. 
CSR research more than whether theists can rationally believe that God exists.

Before commencing our treatment of the CSR objection, two epistemic terms of art need to be addressed. Firstly, there is a distinction between individual epistemology and social epistemology. The first makes normative assessments of a specific agent's beliefs, e.g., that an agent $S$ 's belief that $p$ is warranted or rational or justified or known if and only if conditions $C_{1}, \ldots, C_{\mathrm{n}}$ are satisfied. The second differs in that normative assessments are made about an entire community's belief(s). We understand the methodology of social epistemology to begin with an assessment of which method or cognitive process a group uses to produce a certain belief and then to judge the epistemic status of that belief, the judgment naturally applying to all agents in that community. An adequate treatment of the CSR objection must take into account this distinction for it is unclear whether CSR objectors have specific theists in mind or intend their remarks to apply to all theists.

Secondly, knowledge is factive-only true propositions can be known. Without thereby begging the question, it makes little sense for the CSR objection to be framed on the assumption that theism is false for then it would be trivially true that theistic belief is unsafe. The CSR literature would then be irrelevant to the claim that theistic belief is unsafe. We therefore interpret the CSR objector as making the very interesting claim that despite it being true that God exists, God cannot be known to exist. ${ }^{6}$ Given the conceptual dependence of assertion, practical reasoning, and evidence on knowledge in Williamson's framework (ibid.: 184ff), such a challenge is a serious one indeed.

III.

As adverted to earlier, we think that the CSR objection can be formulated into two different arguments to the conclusion that the belief that God exists is unsafe. An independent discussion of each objection follows.

${ }^{6}$ The same point can be made with respect to interpreting the CSR objector as claiming that theistic belief is unjustified, where justification is understood as a property supervening on the reliability of a cognitive process. 


\subsection{The Counterfactual Argument}

Recall that one does not know it is noon by looking at a broken clock that fortuitously just so happens to correctly read noon. That the agent would have falsely believed it noon even if it were not noon is one way of explaining why agents who look at broken clocks fortuitously reading the correct time are denied knowledge. On similar grounds, the CSR objector might have the following argument in mind:

(1) If God did not exist human beings would still believe that God exists (given that humans are primed to believe in supernatural agents independent of whether or not such agents exist).

(2) Therefore the belief that God exists is unsafe.

The cogency of this argument turns on the first premise, which is expressed in the form of a counterfactual. There are three reasons why this argument fails. Firstly, those familiar with the history of knowledge accounts in the post-Gettier period will recognize that the type of counterfactual expressed by (1) corresponds to Robert Nozick's sensitivity condition for knowledge. According to Nozick (1981: 171), an agent $S$ does not know $p$ if it is the case that were $p$ false $S$ would still believe $p$. It is now widely recognized that the sensitivity condition for knowledge is inadequate in several respects. ${ }^{7}$ That theistic belief fails to satisfy the sensitivity condition for knowledge in light of evolutionary cognitive science is therefore irrelevant.

Secondly, the Counterfactual Argument is invalid as it is not the case that if a belief fails the sensitivity condition it is therefore unsafe; that is to say, a failure of sensitivity does not entail a lack of safety. For example, in some cases sensitivity is the more stringent condition, whilst in others safety is. The following two points of logic elicit the difference between the safety and sensitivity conditions. When it comes to cases concerning knowledge of the denial of skeptical hypotheses the safety principle is less demanding than the sensitivity principle. The sensitivity principle requires that the agent not believe $p$ in the nearest possible world in which

${ }^{7}$ For some reasons counting against the sensitivity condition, see Goldman (1986: 45-6). 
$p$ is false. As such no agent can know the denial of skeptical hypotheses, e.g., "I am not a brain in the vat," by the simple sensitivity test because in the nearest possible world in which the agent is a brain in the vat the agent continues to believe that he is not a brain in the vat.

The safety principle, however, permits knowing the denial of skeptical hypotheses. By the safety principle I count as knowing the everyday proposition $p$ "that I have hands" only if I safely believe $p$. It follows, then, that if I safely believe $p$ then there is no close world in which I am a brain in the vat and am led to falsely believe that I have hands. Consequently, if I know that I have hands and I know that that entails that I am not a brain in the vat, then I know that I am not a brain in the vat.

On the other hand, cases can be constructed in which safety is more demanding than sensitivity. Suppose $S$ truly believes $p$ in the actual world but (i) in the closest world in which $p$ is false $S$ does not believe $p$, and (ii) there is a close world in which $S$ falsely believes $p$. In this case $S$ satisfies the sensitivity condition but fails to satisfy the safety condition. The following case illustrates this point. Unbeknownst to Mary the thermometer she has just purchased is defective and will always yield a reading of $39^{\circ} \mathrm{C}$ regardless of her temperature. Mary, who is running a fever of $39^{\circ} \mathrm{C}$, then uses the thermometer to measure her temperature and it just so happens to correctly read her temperature of $39^{\circ} \mathrm{C}$. However, in the nearest world in which her temperature is not $39^{\circ} \mathrm{C}$ and she uses this thermometer to take her temperature, she is distracted by her son and she doesn't form any belief about her temperature. She accordingly satisfies the sensitivity condition for knowledge. However, there happens to be a non-closest close world in which Mary, who is running a fever of $38.5^{\circ} \mathrm{C}$, uses this thermometer to take her temperature and consequently forms the false belief that her temperature is $39^{\circ} \mathrm{C}$. Mary thus fails to satisfy the safety condition.

In light of the complicated relationship between the sensitivity and safety conditions for knowledge, with respect to any belief $p$ it is not the case that failure of the sensitivity condition entails failure of the safety condition. The counterfactual argument is therefore invalid.

A third reason to discount the Counterfactual Argument is a semantic one. According to the standard Lewisian semantics for counterfactuals, a counterfactual with an impossible antecedent is vacuously true (Lewis 1973: 24). For example, the counterfactual (3) "If frogs were numbers, 
pigs would fly" is true but vacuously so. As discussed earlier, we have interpreted the CSR objector as putting forward her objection on the assumption that God exists. On standard conceptions of God's existence, if God exists he exists necessarily. That is to say, he exists in every possible world. Therefore by the CSR objector's own lights the antecedent of (1) is impossible. Asserting (1), therefore, amounts to no more than asserting (3). There is thus ample reason to discredit the Counterfactual Argument.

\subsection{The Argument from Testimony Chains}

Reliability, as a property of a belief-forming method, comes in different kinds, two of which are important for the purpose at hand-local and global. The latter refers to a method $M$ 's reliability in producing a range of token output beliefs in different propositions $P, Q, R, \ldots$, etc. A method $M$ is globally reliable if and only if it produces sufficiently more true beliefs than false beliefs in a range of different propositions. For example, $M$ could be the visual process and $P$ the proposition that there is a pencil on the desk, $Q$ the proposition that there are clouds in the sky, and $R$ the proposition that the bin is full. If a sufficiently high number of $P$, $Q, R, \ldots$ are true, then method $M$ is globally reliable. A method $M$ is locally reliable with respect to an individual target belief $P$ if and only if $M$ produces a sufficient ratio of more true beliefs than false beliefs in that very proposition $P$. Method $M$, e.g. the visual method, is locally reliable with respect to the belief $P$ if and only it produces a sufficiently high ratio of true beliefs about the presence of the pencil on the desk. ${ }^{8}$

According to Williamson, for a belief to count as safe it must, amongst other things, be the product of a globally reliable method or basis: "If in a case $\alpha$ one knows $P$ on a basis $B$, then in any case close to $\alpha$ in which one believes a proposition $P^{\star}$ close to $P$ on a basis close to $B, P^{\star}$ is true" (Williamson 2009: 325). In light of these considerations, the CSR objector might have the following argument in mind:

${ }^{8}$ At this point we remain neutral on whether reliability should be understood as actual reliability à la McGinn (1999) or as counterfactual reliability à la Goldman (2000). 
(3) The basis on which the theist believes that God exists is globally unreliable.

(4) Therefore, the belief that God exists is unsafe.

According to Barrett, the basis on which theistic belief arose involves the interaction of HADD, MCI's, and other mental tools, ToM in particular. For the sake of ease, let us call this set of mental tools HADD+. On the simplifying assumption that these constitute a singular basis of belief, HADD+, so the CSR objection argues, is globally unreliable as HADD+ generates many false positives. Hence, the doxastic products of HADD+ are unsafe. The above argument is therefore valid and theistic belief unsafe.

As discussed earlier, the distinction between individual and social epistemology must be kept in mind when assessing the CSR objection. It is unclear which theist is the target of this argument. With respect to the contemporary theist, it is controversial whether (i) said theists come to believe that God exists on the basis of HADD+, and (ii) whether HADD+ is globally unreliable. Concerning (i), some contemporary theists believe that God exists either via testimony or as the result of an argument, neither of which involves HADD+. With respect to (ii), even were the contemporary theist to believe that God exists on the basis of HADD+, today we use HADD+ in a fashion that is globally reliable; that is, we form more true than false beliefs about agents in our environments. So the above argument is irrelevant to most contemporary theists.

Suppose, however, we concede the truth of (3) for the very earliest theists because they were using HADD+ in ways that generated many false positives; that is to say, for these very early theists their HADD+ may have been globally unreliable. Therefore, with respect to these very early theists the belief that God exists was unsafe. Given this supposition, the CSR objector might have the following argument in mind:

(5) On the basis of HADD+ some primordial human beings came to believe that God exists.

(6) In these primordial human beings HADD+ was a globally unreliable basis for belief. 
(7) Beliefs produced by globally unreliable methods do not constitute knowledge.

(8) Therefore, these primordial human beings did not know that God exists.

(9) Contemporary theists believe that God exists via testimony chains originating with these primordial human beings.

(10) A testimony chain that does not begin with knowledge cannot yield knowledge to the recipient at the termination of that testimony chain.

(11) Therefore, contemporary theists don't know that God exists via such testimony chains.

The Argument from Testimony Chains seeks to undermine the epistemic status of theistic belief by identifying its epistemically suspect causal origins. It goes without saying that the causal origin of a belief $p$ can be important to the epistemic status of $p$. For instance, I cannot know $q$ if I believe $q$ on the basis of an inference from $p$, and where I do not know $p .{ }^{9}$

As has been conceded, (5)-(8) may indeed be true. And given that many contemporary theists believe that God exists via testimony, (9) may be true as well. (10), however, is false. An agent $S_{2}$ can safely believe a true proposition $p$ via testimony from an agent $S_{1}$ even if $S_{1}$ does not safely believe $p$. Consider the following case from Lackey (2008: 48). It is plausible that a child knows that modern-day homo sapiens evolved from homo erectus when taught so by her teacher, even though her teacher is a religious fundamentalist who does not believe that evolution is true. In this case the child's belief is safe despite the teacher not believing that modern-day homo sapiens evolved from homo erectus and therefore not knowing as much (on the assumption that knowledge entails belief). Testimony can thus be an epistemically generative process-it may permit the hearer to gain something the speaker lacks.

So much for testimony from one person to another. But what about testimony chains? Might a testimony chain that originates with a person who does not safely believe $p$ prevent the person at the termination of the chain from knowing $p$ ? An extrapolation of the foregoing case proves

${ }^{9}$ See Goldman (1986: 52) for a further case demonstrating the importance of a diachronic approach to epistemic status. 
that safe belief is possible for an agent at the termination of such a chain. Suppose Billy, one of the children in the biology class, tells his best friend Jack that modern-day homo sapiens evolved from homo erectus (and would not have easily deceived Jack in this case). We take it that Jack also counts as safely believing that modern-day homo sapiens evolved from homo erectus. And so on. And surely the contemporary theist, relying on the testimony of her parents or community, counts as knowing that God exists even if that testimony chain originated in a primordial ancestor who did not know that God exists. With respect to the contemporary theist, at least, the Argument from Testimony Chains is unsound. ${ }^{10}$

In light of these considerations, the CSR objector may concede that whilst (10) is not a universally true principle, there are cases in which it does hold and that the genesis of theistic belief according to CSR is just such a case. For example, if I truly believe that the train is about to depart on the basis of testimony from someone who read a departure schedule riddled with mistakes, it seems that my belief does not count as safe. The contemporary theist is in a similar position, so the CSR objector might argue, if she believes that God exists based on a testimony chain originating in an ancestor who came to believe that God exists on the basis of a globally unreliable method.

There is room to argue, however, that exceptionally long testimony chains with unsafe origins exhibit some unique epistemic features. We argue that a case can be made for there being a sense in which the primordial human $(S 1)$ is a reliable testifier and as such the contemporary theist $(S N)$ can safely believe that God exists from a testimony chain originating with $S 1$ even if S1 used the globally unreliable HADD+ to arrive at theistic belief. For the sake of argument consider a case in which $S 1$ holds a set of beliefs $\{P, Q, R, \ldots\}$ and that many of these beliefs are generated by HADD+. $S 1$ testifies to others a great many of the beliefs she holds overall. Let us stipulate further that $P$ is the belief that God exists and is one of the few true beliefs in the set $\{P, Q, R, \ldots\}$. S1 is thus an unreliable testifier (as the CSR objector contends). Assume further, and

${ }^{10}$ We are aware that this is not an uncontentious claim to make as many epistemologists require the speaker to know $p$, amongst other things, in order for the hearer to know p, e.g. Burge (1993), Plantinga (1993: 86), and Nozick (1981: 187). But the prima facie plausibility that Billy knows that modern-day homo sapiens evolved from homo erectus brings into question the veracity of the traditional view. 
not unreasonably, that as time passes humans develop mentally. As they do, the testimony chains passing along beliefs $Q, R$, and the other false beliefs in the set "die out" or "dry up" because people come to realize that $Q, R$, etc. are false. We call this feature of long testimony chains epistemic winnowing; individuals and communities do not generally pass along information they deem false. And epistemic winnowing is something we expect others in our community to be committed to. ${ }^{11}$ By the time $S N$ receives the testimony that $P$ from a testimony chain originating with $S 1$, there are no false beliefs from S1's mouth that are passed along anymore; if so, from $S N$ 's perspective, at least, $S 1$ is a reliable testifier.

One can explain this conclusion in terms of safety: there is no close world in which $S N$ falsely believes $P$ or any other relevantly similar belief by way of a testimony chain originating with $S 1$. It seems reasonable to us that the contemporary theist who believes by way of such a long testimony chain is the beneficiary of epistemic winnowing. Therefore, even if the testimony chain by which a contemporary theist believes that God exists has an unsafe genesis, the belief held thereby is safe. The Argument from Testimony Chains is thus unsuccessful.

Additionally, it is doubtful that many contemporary theists believe that God exists on the basis of an extremely long testimony chain that originates in an unreliable theistic ancestor. It is more likely that a considerable number of contemporary theists believe on the basis of a religious experience. Given that for most of us HADD+ is globally reliable, it stands to reason that were HADD+ the basis on which theistic belief is formed as a result of these religious experiences, such theistic belief would be safe.

IV.

We have presented two different ways in which the cognitive science of religion might be used to generate an argument towards the conclusion that the belief that God exists is unsafe. For a number of diverse reasons each argument fails. This failure does not entail that belief in God is safe, however. That would require a separate consideration of its own. (2010).

${ }^{11}$ For the role of one's community in the epistemology of testimony, see Goldberg 


\section{BIBLIOGRAPHY}

Atran, S. 2002. In Gods We Trust. New York: Oxford University Press.

Barrett, J. 2004. Why Would Anyone Believe in God? Walnut Creek, CA: AltaMira Press.

Barret, J. 2009. “Cognitive Science, Religion, and Theology." In: Schloss, J. \& Murray, M.J. (eds.). The Believing Primate: Scientific, Philosophical, and Theological Reflections on the Origin of Religion. Oxford: Oxford University Press, pp. 76-99.

Bering, J.M. 2006. “The Folk Psychology of Souls.” Behavioral and Brain Sciences 29: 453-62.

Bering, J.M. 2011. The Belief Instinct: The Psychology of Souls, Destiny, and the Meaning of Life. NY: Norton.

Bloom, P. 2005. “Is God an Accident?” Atlantic Monthly 296: 105-12.

Boyer, P. 2001. Religion Explained: The Evolutionary Origins of Religious Thought. NY: Basic Books.

Burge, T. 1993. “Content Preservation.” Philosophical Review 102: 457-88.

Clark, K. \& Barrett, J. 2010. "Reformed Epistemology and the Cognitive Science of Religion." Faith and Philosophy 28 (2), pp. 174-189.

Clark, K. \& Barrett, J. Forthcoming. "Reidian Religious Epistemology and the Cognitive Science of Religion." Journal of the American Academy of Religion.

Dawkins, Richard. 2006. The God Delusion. Boston: Houghton Mifflin.

Dennett, D. 2006. Breaking the Spell: Religion as a Natural Phenomenon. New York: Viking.

Gettier, E. 1963. “Is Justified True Belief Knowledge?” Analysis 23: 121-3.

Goldberg, S. 2010. Relying on Others. Oxford: Oxford University Press.

Goldman, A. 1986. Epistemology and Cognition. USA: Harvard University Press.

Goldman, A. 2000. "What is Justified Belief?" In: Kim, J. \& Sosa, E. (eds.). Epistemology: An Anthology. UK: Blackwell, pp. 340-354.

Hawthorne, J. \& Stanley, J. 2008. “Knowledge and Action.” Journal of Philosophy 105 (10): 571-90.

Lackey, J. 2008. Learning from Words: Testimony as a Source of Knowledge. Oxford: Oxford University Press.

Lewis, D. 1973. Counterfactuals. Oxford: Blackwell.

McGinn, C. 1999. “The Concept of Knowledge.” In: McGinn, C. Knowledge and Reality: Selected Essays. Oxford: Oxford University Press, pp. 7-35.

Murray, M. 2009. "Scientific Explanations of Religion and the Justification of Religious Belief.” In: Schloss, J. \& Murray, M (eds.). The Believing Primate: 
Scientific, Philosophical, and Theological Reflections on the Origin of Religion. Oxford: Oxford University Press, pp. 168-178.

Nozick, R. 1981. Philosophical Explanations. Oxford: Oxford University Press.

Plantinga, A. 1993. Warrant and Proper Function. Oxford: Oxford University Press.

Pritchard, D. 2005. Epistemic Luck. Oxford: Oxford University Press.

Pritchard, D. 2009. Knowledge. London: Palgrave Macmillan.

Shope, R. 1983. An Analysis of Knowing: A Decade of Research. Princeton: Princeton University Press.

Sosa, E. 1999. "How must knowledge be modally related to what is known?" Philosophical Topics 26 (1\&2): 373-384.

Wilson, D.S. 2002. Darwin's Cathedral: Evolution, Religion, and the Nature of Society. Chicago: University of Chicago Press.

Williamson, T. 2000. Knowledge and its Limits. Oxford: Oxford University Press.

Williamson, T., 2009. "Reply to John Hawthorne and Maria Lasonen-Aarnio." In: Greenough, P. \& Pritchard, D. (eds.). Williamson on Knowledge. Oxford: Oxford University Press, pp. 313-29. 